\title{
Critical Moments in Elite Premiership Football: Who Do You Think You Are?
}

Authors' contribution:

A) conception and design of the study

B) acquisition of data

C) analysis and interpretation of data

D) manuscript preparation

E) obtaining funding

\author{
Mark Nesti ${ }^{\text {A-D }}$, Martin Littlewood ${ }^{\text {A-D }}$, Lisa O'Halloran ${ }^{\text {D }}$, \\ Martin Eubank ${ }^{\mathrm{A}-\mathrm{D}}$, David Richardson ${ }^{\mathrm{A}-\mathrm{D}}$ \\ Liverpool John Moores University, UK
}

ABSTRACT

The present paper aims to specifically outline the critical moments that permeate professional football players' development and existence in elite level English Premiership football. It also recognises the role of the applied sport psychologist in working with top players to address issues that challenge, impact (and change) player identity and personal meaning as they travel through their career from youth to professional to retirement. We conclude the paper by introducing some alternative perspectives on theory and practice. The paper is a result of the combined interests and applied activity of the authors and draws from theoretical frameworks and concepts in social psychology, existential phenomenological psychology and sociology. In this regard the paper attempts to synthesise (and celebrate) complimentary disciplines in order to allow us to consider the individual player within their social context.

KEYWORDS

critical moments, football, identity

Professional football in England, especially the English Premier League (EPL), presently receives much media and academic attention into its inner working practices and functions. The early work of the journalist Hunter Davies at Tottenham Hotspur in 1971/72 was one of the very first inside accounts into the world of elite professional football, whilst Parker's (1995) ethnographic account of the lived experiences of youth trainees provided a sociological case study account of masculine construction. The world of professional football has changed considerably in the last 15 years. The formation of the Premier League in 1992 and its association with Sky Television now means that English clubs are (perceived to be) equipped with the financial capabilities to attract some of the best talent in the world. These patterns of football labour migration have been heavily researched (see Maguire and Pearton, 2000; Littlewood, 2005; Elliott and Weedon, 2010; Littlewood, Mullen and Richardson, 2011; Weedon, 2011; Richardson, Littlewood, Nesti, Benstead, in Press) and questions relating to indigenous home-grown player progression are central to this body of work. Formal structures and processes were established in 1998 with the creation of Football Academies to identify, develop and select talented young football players. Similarly, attention has focused on Academies in terms of ensuring that they are equipping players with the appropriate skills, qualities and characteristics for successful progression and/or failure (see Richardson et al., 2004, 2005). Most recently, the FA have announced an initiative called The Elite Player Performance Plan (EPPP) as a way of improving the development of home-grown talent in England. The introduction of the EPPP in the 2012-2013 season 
within English professional soccer aims to re-shape the recruitment practices of professional clubs. The EPPP aims to modernise the existing academy system with a remit to promote excellence, nurture talent and systematically convert talented players into professional first team players (The Premier League, 2011). This initiative will see the Premier League and FA invest more central income than ever before in Youth Development programmes across the country.

The modern top-level football club is a multi-faceted business domain that operates within the (football) entertainment industry. As huge service enterprises clubs (sport organisations) must compete on both a financial and sporting level. The massive commercialisation of the football industry demands rigorous and stringent management practices. However, the football world is unique, in that it is a hostage to the weekly (if not twice weekly) performance lens. The intensity of a weekly performance and outcome oriented environment is not replicated in many (if any) other high performance sporting domains. The "shortermism" of football (i.e., a need to win, avoid relegation and survive at all costs) undoubtedly impacts the organisational position, philosophy and subsequent operating culture of the organisation. Such intense pressure suggests that people operating within this world will be exposed to, and have to operate under, intense organisational stress.

Although not dealing with Premiership football, research by Woodman and Hardy (2001) identified that the predominant organisational stressors are related to basic communication failures, a limited awareness or ambiguity concerning organisational direction alongside a lack of role definition and/or duplicity of role. From an organisational perspective any role conflict, role ambiguity, role uncertainty and/or role overload will lead to staff dissatisfaction and ultimately a breakdown of the organisational system and sub-systems (Fletcher and Wagstaff, 2009). Football, it appears, is not immune to such organisational stressors. Indeed, despite a call from UEFA (2005) to develop effective management strategies, Relvas et al. (2010) evidenced a dearth of formal (written), clear and coherent strategic and philosophical practices and positions within toplevel football clubs across Europe. Whilst positing a more coherent framework for organisational practices, Relvas et al. (2010) also recognised that each top-level club was a hostage to the specific cultures and subcultures and working practices that existed in each club (i.e., regardless of which country they were located). Culture, in this sense, captures the patterns of (historically evolving) behaviour and values that form the core template from where working practices, ideas, strategies and philosophies are transferred from one generation, group or individual to another (Wilson, 2001). To this end, organisational culture is more than simply defining organisational conduct through mission statements, vision(s) and/or values. From a research and practitioner perspective it is important to recognise that understanding culture requires an understanding of sociology, anthropology and social psychology. Furthermore, practitioner and researchers alike must recognise that it is the combined work of ALL relevant stakeholders of the organisation that play a key role in determining the organisations aims, working practices, culture and subsequent success. Organisations will benefit from the enhanced performance of their stakeholders through a better understanding and subsequent implementation of more effective, well communicated (coherent and meaningful) strategy.

At this juncture, it is important to re-iterate that the short-term and long-term future of the top-level football club is dependent on results. The sport psychologist working in this context must carry this knowledge with him/her at all times. At the most basic level this means that all activities are directed towards winning, and that managers, support staff and the sport psychologist will most usually lose their jobs if they do not deliver the required results (Nesti, 2010). Excellent performances, sound processes around recruitment, player welfare, administration and other similar matters will be irrelevant if results are not achieved. There are few business environments where these factors are so clear, or where great success can be followed very rapidly by abject failure.

The sports psychologist and aligned practitioners must recognise that the players have to operate within this operational culture at an individual level. Although the established first team players may be protected (to some degree) by contracts that often cover 3 or 4 year durations, ultimately they are judged on their performances and results in games. This creates heightened stresses that are experienced by the individual and subsequently permeate the organisation. The elite level football player may also experience 
stress during difficult periods that relate to negative media coverage, intense criticism from the manager and coaching staff, threats of de-selection and on occasion, antagonism from other team mates, especially those who are not currently in the starting team.

To put this latter point in to context, the typical English Premier League first team squad contains upwards of 25 players. Only 11 can play; with 5 on the substitutes' bench. Given a couple of injuries this can leave 7 players (i.e., 7 potentially disaffected and disillusioned players). There are other moments that the player must deal with which occur when the team or individual players are performing well and achieving success. For the academy player this could take place where they are rewarded for their progress by being invited to train with the first team, secure a professional contract or accepted onto a scholarship. In these more welcome situations, Premiership players may be offered new or improved contracts, receive positive coverage in local, national and international media, and feel secure as established and key members of the team.

The volatile culture of English Premiership football at both an academy and a first team level is such, that for some players and teams, they may encounter very positive and negative situations several times across one season and many times over their careers. The ability to deal with the stress that accompanies these experiences depends on a number of psychological factors. For example, mental toughness has been identified by Crust (2007) as being arguably the most important attribute that elite athletes possess. Although their research was not with elite level professional footballers, work by Crust, Nesti and Littlewood (2010) identified that for academy players in a Premiership club, mental toughness was seen by coaches as the key ability that was necessary to deal with the range of stressors encountered by young players as they passed through this environment. It may be possible to describe these experiences as involving transitions. In recent years a substantial amount of research has been directed at investigating transitions in sport. However, much of this has focused on retirement. This literature has (typically) examined the process of transition that an athlete must face as they cease to be involved as a participant in their sport. A number of different perspectives have been adopted to explain this moment in the life of an athlete. For example Grove et al. (1997) have used an account making model to understand this experience and Sparkes (1998) has focused on the loss of self.

Transition literature has helped develop an understanding around the experiences that athletes face as they leave sport, however, it could be criticised for focusing more so on retirement rather than considering the important transitions facing an athlete throughout their career. Fortunately, work by Pummel, Harwood and Lavallee (2008) has begun to address this important omission by considering within-career transitions. This research, in event riding, offers a promising new line of enquiry, but there is arguably a more fundamental issue that appears to have been over looked. Put simply, the term transition could easily be interpreted as signifying something that is rather smooth, steady and relatively easy to negotiate. A more useful and dramatic phrase that could be used to signify these situations is that of "critical moments". These could be described as being those frequently experienced moments in our lives where we must confront the anxiety associated with an important change in our identity. These can be around personal, professional or vocational matters, and may be described in negative or positive terms. Within the career of a Premiership footballer, these could be related to moments such as being dropped permanently from the team, being sold to another club, being appointed as the team captain, dealing with career threatening injury, illness, and family and relationship difficulties (Nesti and Littlewood, 2011). Indeed critical moments can range from something to nothing, can be large or small, intended or unintended, and may have a negative or positive effect on a person's sense of self (self awareness and self knowledge). Ultimately, a critical moment will involve the subjective lived experience of the individual, will invoke an emotional response and be dependent on timing (i.e., the individual's personal and contextual circumstances at the time). 


\section{Critical moments in professional football}

The example that follows demonstrates how critical moments can impact on a Premiership or elite professional player at any time within their career. The material presented here is derived from the applied practice of the first author. This involved over 9 seasons of sport psychology work inside several EPL clubs, delivering confidential one to one sessions with first team players. Critical moments can impact on the motivation, confidence, stress, and anxiety levels experienced by an individual. Where a sport psychologist is working with a player who is experiencing a critical moment, there is an opportunity to assist the player to use this experience to learn more about themselves and grow psychologically:

\section{Vignette 1}

The player had been at the club for eighteen months since being recruited from a lower league team. They had been one of the star players at their previous club, and had very rarely been dropped from the starting eleven over three seasons. They had come to the Premiership club for a considerable transfer fee, having been the second highest goal scorer at their former club in their final season. The player had very recently been selected to represent their country at international level. However, during the past three months of this season the player had only played on two occasions in the first team, and one of these had been as a substitute. The dialogue with the sport psychologist focussed on identifying what they could do to return to a place in the starting eleven. The player described that he was motivated towards his training, felt very confident and had settled in well amongst his teammates. He also described how his family had settled into the area and that the relationships with the coaching staff and the manager were generally positive and professional. One of the problems that he identified related to the emergence of a young local player in his position. This individual had been a regular starting player during most of the past three months, and their performances were excellent and had begun to attract attention from a number of other Premiership clubs. The success of this player had been a surprise to the coaches and manager at the club; however their form and accomplishments in front of goal meant that they were an automatic choice to play each week. When a player is faced with this situation, there is an urgent need for them to respond positively. Within Premiership football, there is great importance attached to maintaining visibility within the team. The media, supporters and professional staff within the game, can very quickly question the ability and motivation of a player who is unable to break back into the first team. For the individual themselves, this can create a very uncomfortable set of circumstances, where the clearest solution appears to be to maintain performance levels and wait for the other player in your position to become injured, lose form, or fall out of favour. The sport psychologist and player considered how they had managed to deal with similar experiences earlier in their career. However, a major difference in this situation was that he was now an international player, and that the expectations around what he could bring to this club were higher than anything he had previously dealt with. The player discussed options around leaving the club permanently in the summer, or meeting the manager to request a move away even to a lower placed side. However, the player rejected these options after careful thought and deliberation, and decided to, in his words, "stay and fight to get my place in the team back for good". This type of critical moment can serve to strengthen a player's sense of self, ability to cope with stressful situations, mental toughness, and many other psychological factors. This could be considered as a potentially positive outcome from a negative experience (Nesti, 2011). However, sometimes such a situation can undermine a player's confidence and self belief, and may contribute to greater performance problems in the future.

When a young player on the verge of becoming an established first team member encounters a critical moment it can provide an opportunity for psychological growth and development. In the case below, the player is trying to make sense of an unexpected challenge, and with the help of the sport psychologist, is attempting to identify a constructive and realistic solution. 


\section{Vignette 2}

Mark was a bit different. He played for our first team a couple of times when he was still an under-19s player. However, we knew that in the following year he was not going to get many chances. So we (the first team coach and the sport psychologist) spoke with him and he went on loan to a second division team... In the beginning he was not very happy with this because he wanted to play in the first team. Now, he is the first one to admit that the experience was instrumental in enabling him to achieve his actual level. I met with him every week, mainly so he didn't feel abandoned by the club. I have to say that this was my own decision, but with the full support of the club's Board. During these meetings, Mark told me that by experiencing the reality of other players in other clubs and the difficulties that they faced, for example the need to win a match to receive the bonus in order to pay their bills... made him (Mark) understand that being a football player is not easy, and if you want to be successful you must work hard... and in his case, take the advantage of the conditions at Aldam City FC...

According to an existential psychology perspective, critical moments always involve anxiety. Referred to by May (1977) as normal anxiety, this can be an opportunity to develop courage. Corlett (1996) described this virtue as involving the capacity to move forward despite not knowing what the outcome will be. In addition, to be defined as a courageous act, he argued that it must be possible for the individual to avoid this choice if they so desire. According to Nesti (2011) it is impossible to speak of important concepts such as the self, willpower, courage and even love without recognising that we as persons are capable of the consciously free act. In other words, this is a choice taken freely and without compunction by the person despite the discomfort of existential anxiety. Premiership players face challenges to their identity repeatedly throughout their careers, and at these critical moments they must find new or different forms of meaning to allow them to continue to progress. The existential view is that the search for meaning might require the player to reassess their values and deepest beliefs which may change or become more central to who they are. This will help them to align their core self with decisions and behaviours they intend to pursue to successfully pass through a critical moment.

Existential anxiety is related to accepting that choices are always available, and that the outcome of such choices is always impossible to fully determine. The player may on occasion experience debilitative competitive anxiety (Jones, 1995). However, anxiety is often experienced beyond factors associated with the competitive event (Nesti, 2004). For example, when a player decides that their career is not progressing as they would wish at a particular club, they are confronted by a number of options. They could seek a move elsewhere, attempt to work harder to get back into their current team, speak to the manager, or accept the situation and opt for an easy life. However, each of these choices will be accompanied by feelings of existential anxiety. This means that in considering what to do next to improve circumstances, the player will feel anxious about what the likely outcome could be. For example, if they decide to put in the transfer request, will they be leaving a club that they could have been successful at in the longer term? What if they cannot move to a better club, and how might this be perceived in the media and the professional game nationally? In addition to a choice like this, there are the difficulties associated with announcing the intention to leave whilst still remaining with your current employers for a considerable period of time, how the supporters may view the defection, and the disruption caused to family where they are settled in the local area. The solution to avoid these uncomfortable feelings of existential anxiety could be for the player to remain where they are and suppress any thoughts they have about possible change. According to the existential perspective, this can bring temporary relief to the feelings of anxiety, but at the expense of diminishing the psychological core of the person, and making them less likely to make difficult choices in the future. If the player in this situation considers all of the available choices, with the support of the sport psychologist, and decides that the best solution is to remain where they are, they will have dealt with the anxiety feelings in a constructive way and because of this, will have grown as a person and a player. This type of anxiety is frequently encountered by Premiership players as they repeatedly experience critical moments across their careers. 
From a more humanistic psychology perspective, Balague (1999) referred to the importance of identity and meaning in her work with sports performers. However, since then, this topic has received very little serious consideration in the literature. Most of the work on athletic identity and identity in sport has been based on trait approaches in psychology. Whilst allowing for measurement and quantification of various factors through use of psychometric tests, trait psychology has a number of important failings. Nesti (2004) and Watson and Nesti (2005) have highlighted some of these and questioned why sport psychology has been dominated by either cognitive or trait psychology. They argue this has been in part due to the lack of knowledge about the wide range of psychological theories that exist in psychology, a desire to measure and control, and unease about less "scientific" paradigms such as psychoanalysis, humanistic or existential approaches.

In one of the most important books influencing the humanistic psychology movement in the 1960's, Maslow (1968) claimed that identity represented the most important concept in understanding an individual's psychological development. That his work, and extensive efforts by others in developmental and educational psychology, has been little used in published research in sport psychology surely represents a missed opportunity. For UK based sport psychologists this situation is, in some ways, even worse. This is because, as Maslow (1968) pointed out, the European movement of existential phenomenological psychology had already been emphasising the importance of meaning and identity in its scholarly writing and research throughout the past 100 years. The ignorance that exists about this approach in the UK suggests that it is just one more example of us uncritically adopting North American perspectives in psychology and ignoring those more close to home. Interestingly, Maslow, who after all is considered to be one of the giants of psychology and the founder of humanistic psychology, claimed that, European existential psychology was the first to place, "a radical stress on the concept of identity as a sine qua non of human nature and of any philosophy or science of human nature" (Maslow, 1968, p. 9). Despite this endorsement, the existential approach to identity has been generally ignored in the work of UK and North American sport psychology research.

This important topic in sport has most usually been studied by drawing on the work of Marcia (1980) to examine athletic identity in college athletes (Good et al.,1993) and retirement from sport (Brewer et al., 2000). Marcia's work is based on Erikson's (1968) psychodynamic approach to personality theory that views identity in terms of stages of crises and resolution. However, as mentioned already, the considerably older approach of existential phenomenology adopts a more fluid perspective towards identity and meaning. Existential phenomenology is a result of the blending of these two interrelated perspectives (Valle et al., 1989) with phenomenology providing existentialism with a method that allows it to describe experience effectively (Dale, 1996). According to Hacker (1994), what is lost within Erikson's (1968) theory of identity development, is the existential phenomenological view that the person exists not only in the present, but is inextricably linked to a past childhood that leads imperceptibly to a future adulthood. According to the existential phenomenological perspective, human beings are constantly faced with; the freedom to make certain choices, the responsibility for each decision we make (the outcome of which cannot be predicted), the finitude of our world and our own being, and the anxiety which is caused by all of these conditions, throughout our existence. This view on existence suggests that one's identity development and structure is forever in a state of flux. Existential phenomenology recognises the importance of the choices and 'tough questions' that human beings are faced with during their life, for example; the meaning of their existence and who they are as individuals. These questions may arise during times of intense pressure, transitions or critical moments when one's identity is being directly threatened. As mentioned before, in the world of elite football pressure, transitions and critical moments occur frequently throughout a career (i.e., their existence in the sport). Erikson's conceptualisation of and theorising around identity transition has therefore been criticised by existential phenomenological psychology for being unable to capture what really takes place during change in identity. In elite football, often times the cause of identity change or crisis cannot be predicted and will happen unexpectedly (e.g. injury/de-selection) and therefore, will not occur in set stages or cycles. It is because of this that it is criticised for being a reductionist account of identity and not sufficiently empirical (i.e., not fully capable of describing reality). 
Although not based on existential approaches, recent work by Brown and Potrac (2009, pp. 154-155) investigating de-selection and identity disruption in elite level youth football reported,

"that, the feelings of loss, uncertainty, failure and disorientation that followed their de-selection from professional football could, in part be considered the consequence of the development of a strong athletic identity".

Although not refuting this finding, our own practice in Premiership football at first team and academy levels (Nesti and Littlewood, 2009) points to the importance of developing a strong, flexible and clear sense of self to be able to perform in such a volatile environment. Drawing on accounts from existential psychology, identity is seen as a very important source of meaning and as something beneficial to the player's health, wellbeing, and ability to perform at their best. It has been suggested by Nesti (2011), that identity conceived in this way, can help the player to successfully confront the anxiety they repeatedly face as they meet the challenges associated with progress or decline in their playing careers and beyond. This process is rarely discrete, neat or tidy, and in many ways must always remain open and unfinished. However, the existential view is that it requires courage to construct or accept a new identity for ourselves (Corlett, 1996) since it involves movement from a secure and known place to something yet to unfold.

On some occasions even very experienced players will lose their way and need to re visit their identity to help them move through a critical moment. In the vignette below, the player asked to meet the sport psychologist to help them to find a solution to a particularly frustrating set of problems they were facing.

\section{Identity as synthesis}

The sport psychologist (SP) agreed to meet with the Premiership player (PP) at the stadium away from the training ground in order to have a more prolonged private meeting.

PP: I am being questioned by lots of people about my motives at this club at the present time, and I don't like what I'm hearing at the moment!

SP: What is your view though, rather than what the media and some others at the club seem to be saying about why you are here and what you are trying to do?

PP: I know this would not sound very good in the outside world, but I have played for many years in the Premiership, and I am not performing for money or so that people talk about me in positive terms! The most important things to me now are about making sure that I finish well, do my job each day, and don't let my standards drop. This means that I will continue to show the real me, whether this is appreciated and understood or not by the manager and one or two other key people. I am committed to helping this club, and to helping the young players step up in the future and keep us at this level. I know what I stand for and who I am!

SP: What exactly are those things though, and how do they help you at this difficult moment?

PP: They are my belief in myself as a top level professional footballer, as someone who has achieved in the sport and knows their strengths and limitations. And, this is about me, the values that are important to me, honesty, integrity, and not being afraid to do things the right way even if this makes things difficult for me at times. I don't want to sound arrogant about this, but I know what should be done, having been in these situations before, and I think it would be impossible for me, would make me feel really frustrated and very unhappy not to be able to follow what I know I should do, in other words to be true to myself.

SP: And how are you dealing with the situation you are in now, where much of the blame for the team's poor performances, are being laid at your door?

PP: These times are very tough and frustrating, and if I had been caught up in how others have viewed me, that is, a "hero" earlier in the season and now in some people's eyes, a "zero", then I would be lost and unable to keep moving forward. At times like this in the past, when I 
was a younger and less experienced Premiership player, I've maybe followed what others wanted me to do even where I knew that these were only short term solutions, or were not likely to bring the best results. I have learned over the years that the most important area of psychological strength for me is based on knowing myself well, and crucially, making sure that I live my football in a way that is consistent with the type of person I am. I have seen others who do not do this, and when difficult times arrive, they can be broken. It makes sense really, because most top players I have been with in my career are equally strong as people as they are as football players. Not to be this would mean that every time you are slaughtered by the papers, insulted by the manager or criticised by your own supporters, would cause a catastrophic decline in your performances. It is not possible in this intense and highly pressured world of Premiership football to live as two separate people for long! Eventually either the footballer will fail, or the non-footballer side of you will refuse to put up with all of this!

This account highlights how extremely challenging moments can force a player to examine their identity. This process allows them to consider how they truly see themselves. The dialogue describes the player's growing awareness that to be able to face this critical moment they need to remind themselves they are not only an elite level footballer but that they also have another important identity beyond their professional role. The player also talks about why it is important to his continued success to take time to clarify his different identities, and acknowledges that each must be integrated into his whole identity. Without this level of identity renewal he recognises that it will be very hard for him to survive and thrive in the transient, volatile, and highly pressured culture that is Premiership football.

\section{Conclusion}

The applied work of Nesti and Littlewood (2009) carried out over 9 seasons with Premiership footballers, especially those at first team level found that the existential perspective on identity, meaning and critical moments has proved useful in understanding the journeys of the players they have worked with. This has helped guide work that has been carried out through one to one counselling sessions with players in clubs aimed at helping them to become more authentic; that is, to become more fully who they really are (Nesti, 2004) which in turn will provide the best basis to use their talents more fully. This existential idea of authenticity (May, 1977) shares much with Maslow's (1968) concept of self-actualisation which relates to the humanistic psychology notion of the fully functioning person.

In this account we have suggested that critical moments should not be seen as rarely encountered negative experiences; rather they provide the athlete with an opportunity to thoroughly examine the choices they face, and to choose a way ahead despite the anxiety that will accompany this decision. This is a path towards greater self-knowledge and authenticity, something that should be strived for although it can never be attained fully. The players in the examples above were engaged in this process with the support of a sport psychologist. The aim of this type of psychological support is to help the person accept that sometimes, pursuing particular courses of action in the future depends less on motivation or feelings of confidence about possible outcomes, and is much more related to congruence between personal identity and choice. This is not an easy thing to achieve, since as we have discussed, the existential anxiety that accompanies critical moments is deeply uncomfortable. The easier but less effective option is to avoid the anxiety by avoiding the need to choose. This may help in the short term but over time choices will have to be made; the closer these are to our real selves, that is, who we think we are, the more likely we will commit to our decisions and see them through.

Finally, it is important to be aware that identity and meaning can not be understood according to the existential view by focusing on the individual in isolation. Existential psychology conceives of the person as an individual located in a cultural context (Nesti, 2007). Indeed, practitioners and researchers alike must extend their thinking to recognise and consider the wider cultural and social landscape that surrounds toplevel athletes. This means that research and applied practice in sporting organisations should endeavour to 
examine the individual operating within their culture, sub culture and its practices (i.e., social, anthropological, existential) if it is to be rigorously empirical and capable of capturing the real lives of the athletes.

\section{REFERENCES}

Balague, G. (1999). Understanding identity, value and meaning when working with elite athletes. The Sport Psychologist, 13, 89-98.

Brewer, B.W., Van Raalte, J.L., \& Petitpas, A.J. (2000). Self-identity Issues in Sport Career Transitions. In D. Lavallee and P. Wylleman (Eds.), Career transitions in sport: International perspectives (pp. 29-43). Morgantown, WV: Fitness International Technology.

Brown, G., \& Potrac, P. (2009). 'You've not made the grade, son': de-selection and identity disruption in elite level youth football. Soccer \& Society, 10(2), 143-159.

Corlett, J. (1996). Virtues lost: courage in sport. Journal of the Philosophy of Sport, 23, 45-57.

Crust, L. (2007). Mental toughness in sport: A review. International Journal of Sport and Exercise Psychology, 5, 270290.

Crust, L., Nesti, M., \& Littlewood, M. (2010). A cross sectional analysis of mental toughness in a professional football academy. Athletic Insight Journal, 2(2).

Dale, G.A. (1996). Existential phenomenology: Emphasizing the experience of the athlete in sport psychology research. Sport Psychologist, 10(4), 307-321.

Davies, H. (1972). The Glory Game. Edinburgh: Mainstream.

Elliott, R., \& Weedon, G. (2010). Foreign players in the English Premier Academy League: 'Feet-drain' or 'feetexchange'. International Review for the Sociology of Sport, 46(1), 61-75.

Erikson, E.H. (1968). Identity: Youth and Crisis. New York: Norton.

Fletcher, D., \& Wagstaff, C.R.D. (2009). Organizational psychology in elite sport: Its emergence, application and future. Psychology of Sport and Exercise, 10(4), 427-434.

Good, A.J., Brewer, B.W., Petitpas, A.J., Van Raalte, J.L., \& Mahar, M.T. (1993). Athletic identity, identity foreclosure, and college sport participation. Academic Athletic Journal, 8, 1-12.

Grove, R.J., Lavallee, D., \& Gordon, S. (1997). Coping with retirement from sport: The influence of athletic identity. Journal of Applied Sport Psychology, 9, 191-203.

Hacker, D.J. (1994). An existential view adolescence. Journal of Early Adolescence, 14(3), 300-327.

Jones, G. (1995). More than just a game: Research developments and issues in competitive anxiety in sport. British Journal of Psychology, 86(4), 449-478.

Littlewood, M. (2005). The impact of foreign player acquisition on the development and progression of young players in elite level English professional football. Unpublished $\mathrm{PhD}$ thesis, Liverpool John Moores University, UK.

Littlewood, M., Mullen, C., \& Richardson, D. (2011). Football labour migration: An examination of the player recruitment strategies of the 'big five' European football league 2004-5 to 2008-9. Soccer \& Society, 12(6), 788-805.

Maguire, J., \& Pearton, R. (2000). The impact of elite labour migration on the identification, selection and development of European soccer players. Journal of Sports Sciences, 18, 759-769.

Marcia, J.E. (1980). Identity in Adolescence. In J. Adelson (Ed.), Handbook of Adolescent Psychology (pp. 159-87). New York: Wiley.

Maslow, A.H. (1968) Toward a Psychology of Being. New York: Van Nostrand Reinhold Company.

May, R. (1977). The Meaning of Anxiety. New York: Ronald Press.

Nesti, M.S. (2004). Existential Psychology and Sport: Theory and Application. London: Routledge.

Nesti, M.S. (2007). Persons and Players. In J. Parry, M.S. Nesti, S. Robinson and N. Watson (Eds.), Sport and Spirituality: An Introduction (pp. 7-21). London: Routledge.

Nesti, M.S., \& Littlewood, M. (2009). Psychological preparation and development of players in premiership football: Practical and theoretical perspectives. In T. Riley, A.M. Williams \& B. Drust (Eds.), International Research in Science and Soccer. London: Routledge.

Nesti, M. (2010). Psychology in Football: Working with elite and professional players, London: Routledge.

Nesti, M.S. (2011). Sporting recommendations for spiritual encounters: Delivering sport psychology inside the English Premier League. Physical Culture and Sport. Studies and Research, LII, 14-21. DOI:10.2478/v10141-011-0010-z. 
Nesti, M., \& Littlewood, M. (2011). Making your way in the game: Boundary situations in England's professional football world. In D. Gilbourne \& M.B. Andersen (Eds.), Critical Essays in Applied Sport Psychology. Human Kinetics. Parker, A. (1995). Great Expectations: Grimness or Glamour? The Football Apprentice in the 1990s. The Sports Historian, 15, 107-126.

Pummell, B., Harwood, C., \& Lavallee, D. (2008). Jumping to the next level: A qualitative examination of withincareer transitions in adolescent event riders. Psychology of Sport \& Exercise, 9, 427-447.

Relvas, H., Littlewood, M., Nesti., M., Gilbourne, D., \& Richardson, D. (2010). Organisational structures and working practices in elite European professional football clubs: Understanding the relationship between youth and professional domains. European Sport Management Quarterly, 10(2), 165-187.

Richardson, D., Gilbourne, D., \& Littlewood, M. (2004). Developing support mechanisms for elite young players in a professional soccer academy. European Sport Management Quarterly, 4, 195-214.

Richardson, D., Littlewood, M., \& Gilbourne, D. (2005). Homegrown or Home Nationals? Some Considerations on the Local Training Debate. Insight Live https://ice.thefa.com/ice/livelink.exe/fetch/2000/10647/466509/477135/477257/ Homegrown_or_Home_Nationals._The_Case_for_the_Local_Training_Debate.?nodeid $=675785 \&$ vernum $=0$

Richardson, D., Littlewood, M., Nesti, M., \& Benstead, L. (in Press). An examination of the migratory transition of elite young European soccer players to the English Premier League. Journal of Sports Sciences.

Sparkes, A. (1998). Athletic identity: An Achilles heel to the survival of self. Qualitative Health Research, 8, 644-664.

The Premier League (2011). Elite Player Performance Plan May 2011. Premier League, London.

Valle, R.S., King, M., \& Halling, S. (1989). Existential-phenomenological Perspectives in Psychology. London: Plenum Press.

Watson, N.J., \& Nesti, M. (2005). The role of spirituality in sport psychology consulting: An analysis and integrative review of literature. Journal of Applied Sport Psychology, 17, 228-339.

Weedon, G. (2011). 'Glocal boys': Exploring experiences of acculturation amongst migrant youth footballers in Premier League academies. International Review for the Sociology of Sport, 1-17.

Wilson, A.M. (2001). Understanding organisational culture and the implications for corporate marketing. European Journal of Marketing, 35(3/4), 353-367.

Woodman, T., \& Hardy, L. (2001). A case study of organizational stress in elite sport. Journal of Applied Sport Psychology, 13(2), 207-238.

AUTHOR'S ADDRESS:

\author{
Mark Nesti \\ Research Institute for Sport and Exercise Sciences, \\ Tom Reilly Building, \\ Liverpool John Moores University \\ Byrom St., L3 5AF \\ UK \\ Email: M.S.Nesti@ljmu.ac.uk
}

